Subscriber access provided by University of Greenwich

\title{
Article
}

\section{Molecular modelling as a predictive tool for the development of solid dispersions}

Mohammed Maniruzzaman, Jiayun Pang, David J. Morgan, and Dennis Douroumis

Mol. Pharmaceutics, Just Accepted Manuscript • DOI: 10.1021/mp500510m • Publication Date (Web): 03 Mar 2015

Downloaded from http://pubs.acs.org on March 12, 2015

\section{Just Accepted}

"Just Accepted" manuscripts have been peer-reviewed and accepted for publication. They are posted online prior to technical editing, formatting for publication and author proofing. The American Chemical Society provides "Just Accepted" as a free service to the research community to expedite the dissemination of scientific material as soon as possible after acceptance. "Just Accepted" manuscripts appear in full in PDF format accompanied by an HTML abstract. "Just Accepted" manuscripts have been fully peer reviewed, but should not be considered the official version of record. They are accessible to all readers and citable by the Digital Object Identifier (DOI®). "Just Accepted" is an optional service offered to authors. Therefore, the "Just Accepted" Web site may not include all articles that will be published in the journal. After a manuscript is technically edited and formatted, it will be removed from the "Just Accepted" Web site and published as an ASAP article. Note that technical editing may introduce minor changes to the manuscript text and/or graphics which could affect content, and all legal disclaimers and ethical guidelines that apply to the journal pertain. ACS cannot be held responsible for errors or consequences arising from the use of information contained in these "Just Accepted" manuscripts. 


\title{
Molecular modelling as a predictive tool for the development of solid dispersions
}

\author{
Mohammed Maniruzzaman ${ }^{1}$, Jiayun Pang ${ }^{1 *}$, David J. \\ Morgan $^{2}$, Dennis Douroumis ${ }^{1}$ * \\ ${ }^{1}$ Department of Pharmaceutical, Chemical and Environmental Sciences, Faculty of \\ Engineering and Science, University of Greenwich, Medway Campus, Central Avenue, \\ Chatham Maritime, Chatham, Kent, ME4 4TB, UK \\ ${ }^{2}$ Cardiff Catalysis Institute, School of Chemistry, Cardiff University, Park Place, Cardiff, \\ CF10 3AT
}

\footnotetext{
${ }^{1}$ To whom correspondence should be addressed: Dennis Douroumis, email: D.Douroumis@gre.ac.uk, Jiayun Pang, email: J.Pang@gre.ac.uk, Department of Pharmaceutical, Chemical and Environmental Sciences, Faculty of Engineering and Science, University of Greenwich, ME4 4TB, Kent, UK.
} 


\begin{abstract}
In this study molecular modelling is introduced as a novel approach for the development of pharmaceutical solid dispersions. A computational model based on quantum mechanical (QM) calculations was used to predict the miscibility of various drugs in various polymers by predicting the binding strength between the drug and dimeric form of the polymer. The drug/polymer miscibility was also estimated by using traditional approaches such as Van Krevelen/Hoftyzer and Bagley solubility parameters or Flory Huggins interaction parameter in comparison to the molecular modelling approach.

The molecular modelling studies predicted successfully the drug-polymer binding energies and the preferable site of interaction between the functional groups. The drug-polymer miscibility and the physical state of bulk materials, physical mixtures and solid dispersions were determined by thermal analysis (DSC/MTDSC) and X-ray diffraction. The produced solid dispersions were analysed by X-ray photoelectron spectroscopy (XPS), which confirmed not only the exact type of the intermolecular interactions between the drugpolymer functional groups but also the binding strength by estimating the $\mathrm{N}$-coefficient values. The findings demonstrate that QM-based molecular modelling is a powerful tool to predict the strength and type of intermolecular interactions in a range of drug/polymeric systems for the development of solid dispersions.
\end{abstract}

Keywords: solid dispersions, quantum mechanics, molecular modelling, miscibility, drugpolymer interactions. 


\section{INTRODUCTION}

Drug-polymer miscibility is a significant factor to consider when designing solid dispersions for pharmaceutical dosage forms ${ }^{1}$. The interactions between small molecule drugs and polymers in a polymeric matrix system determines the nature of the drug loading inside the polymer matrix, such as oversaturated or under saturated, thus play a vital role in determining the long-term stability of the formulated product. Therefore, the characterisation and prediction of drug-polymer miscibility and more importantly drug solubility at various conditions has become an emerging topic in pharmaceutical research for the development of solid dispersions ${ }^{1-3}$. The dispersion of a small drug molecule being miscible into a polymer matrix is mechanistically a complex process. Both the repulsive and attractive intra- and intermolecular forces (e.g. dispersion force, dipole-dipole interaction, and hydrogen bonding forces) present in the system may further complicate the process. As a mechanistic rule, the molecular level mixing requires a step of balancing and/or breaking the crystalline lattice of drug molecules (with high activation energy) in the first instance. Subsequently, the polymer swelling (a process of polymer chain segment absorbing drug molecule) and rebuilding of the possible interactions inside the mixture occur ${ }^{4}$. The drug molecule (either crystalline or amorphous) may have significantly different physical properties within the polymer matrices after processing due to the different energy input and possible inter-molecular interactions that are required to form a solid dispersion. In terms of the random distribution of small drug molecules into the polymeric matrices, the miscible drug content demonstrates amorphous characteristics.

The lattice-based Flory-Huggins $(\mathrm{F}-\mathrm{H})$ theory (Flory 1952) is well known for the prediction of polymer-solvent or polymer-polymer interactions based on the Gibbs free energy change before and after mixing ${ }^{5}$. The F-H theory can be successfully applied to determine the interaction parameter therefore signifying the strength of the interactions between two compounds during their melting. Recent publications applying the $\mathrm{F}-\mathrm{H}$ theory in solid dispersions focus on obtaining the $\mathrm{F}-\mathrm{H}$ interaction parameter, $\chi$, by the melting point depression method 6, 7. The employment of $\mathrm{F}-\mathrm{H}$ theory for the prediction of the intermolecular interactions in pharmaceutical binary systems can provide important insights in the development of solid dispersions processed by hot melt extrusion (HME) for example. However, the theory assumes random distribution of the segments, which may not be suitable in cases where there are strong polar forces or specific interactions, such as hydrogen 
bonding, between the components of the blends ${ }^{8}$. A deeper understanding of the relatively stronger interactions between the drug and the polymer has to be built on insights of the atomic level interactions. Molecular modelling approach is a powerful addition to the F-H theory to characterise the drug-polymer interactions through both visualisation of the interaction and estimation of the strength of the interactions. To date, a number of molecular mechanics (MM)-based molecular dynamics (MD) simulation studies ${ }^{9-12}$ have been performed to study various molecules (e.g. dissolution of the molecules from the crystal surface $)^{13}$ or to identify drug-polymer miscibility in solid dispersions ${ }^{14-18}$. Recently, we ${ }^{19}$ reported the use of quantum mechanical (QM) calculations with commercially available software (Gaussian 09) to characterise possible drug/polymer interactions. Our calculations indicated the existence of hydrogen bonding between the amine group of the drug molecule and the carboxyl groups of the polymer among different drug/polymer formulations, which was subsequently, confirmed by NMR and X-ray photoelectron spectroscopy (XPS) studies.

In recent years, hot-melt extrusion (HME) has undergone a renaissance in the research and development of pharmaceutical formulations ${ }^{20}$. HME is a manufacture processing technology that combines the advantages of a solvent-free solid dispersion and has been used for a wide range of solid dispersion with increased drug solubility, taste masking of bitter APIs, and sustained/controlled release properties ${ }^{20,21}$.

In this study, we developed a new approach to determine the drug-polymer miscibility based on quantum mechanical (QM) calculations, whereby the calculated binding energy between the drug and the polymer provides a strong indication for the formation of stable solid dispersions. The QM approach was compared with the Hansen solubility parameters and F-H estimated values in order to demonstrate the superiority of the molecular modelling approach, which not only provides more accurate description of the drug-polymer interaction energy, but also predicts the interacting functional groups between both substances. The latter was confirmed by X-ray photoelectron spectroscopy (XPS) ${ }^{22,23}$ studies on the produced HME solid dispersions. XPS has been reported as a valuable tool for the characterisation of solid dispersions by providing information on the nature (e.g. H-bonding) and specific site of chemical bonding on the surface of the solid dispersion. 


\section{MATERIALS AND METHODS}

Materials. Propranolol HCl (PRP) and Diphenhydramine HCl (DPD), Paracetamol (PMOL), Ibuprofen (IBU), Dichlofenac Na (Df-Na) and Hydrocortisone (HCS) were purchased from Sigma Aldrich (London, UK) of $\geq 98 \%$ purity. Eudragit L100 (L100), Eudragit EPO (EPO) and Eudragit L100-55 were kindly donated by Evonik Pharma Polymers (Darmstadt, Germany). Kollidon VA64 (VA64) was kindly donated by BASF (Germany). All materials were used as received.

Hot-melt extrusion (HME) processing. Drug/polymer blends (PRP/L100, PRP/L100-55, DPD/L100, DPD/L100-55, PMOL/VA64, IBU/VA64 and IBU/EPO) were blended in $100 \mathrm{~g}$ batches for 10 min each with a Turbula (TF2, Basel) mixer. The extrusion of all batches was performed using a Randcastle single-screw extruder (RCP0625) equipped with a 5-mm rod die at $100^{\circ} \mathrm{C} / 140^{\circ} \mathrm{C} / 155^{\circ} \mathrm{C} / 155^{\circ} \mathrm{C} / 150^{\circ} \mathrm{C}($ Feeder $\rightarrow$ Die) temperature profiles for PRP and DPD based formulations, $100^{\circ} \mathrm{C} / 113^{\circ} \mathrm{C} / 115^{\circ} \mathrm{C} / 115^{\circ} \mathrm{C} / 115^{\circ} \mathrm{C}$ (Feeder $\rightarrow$ Die) for PMOL and $70^{\circ} \mathrm{C} / 85^{\circ} \mathrm{C} / 85^{\circ} \mathrm{C} / 85^{\circ} \mathrm{C} / 80^{\circ} \mathrm{C}$ (Feeder $\rightarrow$ Die) for IBU based formulations. The screw speed was set at $15 \mathrm{rpm}$ for all drug/polymer binary compositions. The produced extrudates (strands) were grinded by using a Ball Mill system (Retsch, Germany) to obtain granules $(<500 \mu \mathrm{m})$ at a rotational speed of $400 \mathrm{rpm}$ for $5 \mathrm{~min}$. The drug-polymers composition consisted of PRP/L100, PRP/L100-55, DPD/L100 and DPD/L100-55 were extruded at ratios of 10/90 w/w. These four extruded formulations (comprising oppositely charged drugs and polymers) were used in XPS analysis to determine possible intermolecular interactions.

Hansen solubility parameters: Predictions of drug/polymers miscibility. The theoretical drug-polymers miscibility was determined by applying the Hansen solubility parameters $(\delta)$ for both drugs as well as the polymers. The Hoftyzer and van Krevelen method was used to calculate all drug polymers solubility parameters by considering the chemical structural orientations ${ }^{24}$ according to the following equation:

$$
\delta^{2}=\delta_{d}^{2}+\delta_{p}^{2}+\delta_{h}^{2}(1)
$$

Here,

$$
\delta_{d}=\frac{\Sigma F_{d i}}{V i}, \delta_{p}=\frac{\sqrt{\Sigma F_{p i}^{2}}}{V i}, \delta_{h}=\sqrt{\frac{\Sigma E_{h i}}{V i}}
$$


$\mathrm{i}=$ structural groups within the molecule, $\delta=$ the total solubility parameter. $\mathrm{F}_{\mathrm{di}}=$ molar attraction constant due to molar dispersion forces, $\mathrm{F}_{\mathrm{pi}}^{2}=$ molar attraction constant due to molar polarization forces, $\mathrm{E}_{\mathrm{hi}}=$ hydrogen bonding energy, and $\mathrm{Vi}=$ group contribution to molar volume

By using the two - dimensional approach Bagley et al. ${ }^{25}$ introduced the volume - dependent solubility parameter which is defined as $\delta \mathrm{v}$, where $\delta_{\mathrm{p}}$ and $\delta_{\mathrm{d}}$ were used to predict the combined thermodynamic effects on the drug-polymers miscibility over hydrogen bonding energy, $\delta \mathrm{h}$.

$$
\delta_{v}=\sqrt{\delta_{d}^{2}+d_{p}^{2}}(2)
$$

Flory Huggins (F-H) theory for the prediction of drug/polymers interaction parameter.

The $\mathrm{F}-\mathrm{H}$ interaction parameter, $\chi$, was correlated with temperature dependence, as in many simplified cases. The interaction parameter of the model system was determined at two different conditions using the Nishi-Wang Eq. $3^{26}$ equation based on melting point depression data and Hildebrand and Scott Eq. $4{ }^{27}$ correlations with solubility parameter, respectively. The F-H interaction parameter $(\chi)$ of the drug/polymers as shown in Table 2 binary mixtures were calculated by using the following equations. The value determined by Eq. 3 represents the interactions between the two substances, specifically at the melting temperature, which may not be extrapolated to other temperatures.

$$
\frac{1}{T_{m}}-\frac{1}{T_{m}^{0}}=-\frac{R v_{d r u g}}{\Delta H_{d r u g} v_{\text {poly }}}\left[\ln \phi_{\text {drug }}+\left(1-\frac{1}{m_{\text {poly }}}\right) \times\left(1-\phi_{\text {drug }}\right)+\chi_{\text {drug-poly }}\left(1-\phi_{\text {drug }}\right)^{2}\right]
$$

Where, $v$ is the molar volume of the repeating unit, $m$ is the degree of polymerization, $\varphi$ is the volume fraction and $\chi$ is the crystalline- amorphous polymer interaction parameter, $\mathrm{T}_{\mathrm{m}}$ is the crystalline melting peak of the pure drugs and $\mathrm{T}^{0}{ }_{\mathrm{m}}$ is the melting endotherm of the drugpolymer physical blends.

F-H interaction parameter $(\chi)$ can be also estimated by the method developed by Hildebrand and Scott according to the following Eq. $4^{27}$.

$$
\chi=\frac{v\left(\delta_{d r u g}-\delta_{p o l y}\right)^{2}}{R T}
$$


Where, $\mathrm{R}$ is the gas constant, $\mathrm{T}$ is the absolute temperature, and $v$ the volume per lattice site and $\delta_{\text {drug }}$ and $\delta_{\text {poly }}$ are solubility parameters of drugs and polymers respectively.

Thermal analysis (DSC and MTDSC). A Mettler-Toledo 823e (Greifensee, Switzerland) differential scanning calorimeter (DSC) was used to carry out thermal analysis of the bulk APIs, polymers, drug/polymer binary physical mixtures and extruded formulations $(n=3)$. About 3-5 mg of each samples were placed in sealed aluminium pans with pierced lids. The samples were heated, cooled and reheated at $10^{\circ} \mathrm{C} / \mathrm{min}$ from $0^{\circ} \mathrm{C}$ to $220^{\circ} \mathrm{C}$ under an atmosphere of dry nitrogen. In addition modulated temperature differential scanning calorimetry (MTDSC) studies were performed from $20^{\circ} \mathrm{C}$ to $150^{\circ} \mathrm{C}$ with an underlying heating rate of $1{ }^{\circ} \mathrm{C} / \mathrm{min}$. The pulse height was adjusted to $1-2^{\circ} \mathrm{C}$ with a temperature pulse width of $15-30 \mathrm{~s}$.

Molecular Modelling. The dimeric structures of L100, L100-55, EPO and VA64 and the monomeric structures of PRP, DPD, PMOL, IBU, Df-Na and HCS were constructed by program Gaussview ${ }^{28}$. Hydrogen bonding patterns were identified by placing the drug molecule within the proximity of the dimeric structure of the polymer and then energy optimised to local minima at the M06-2x/6-31G** level and verified by frequency calculations using Gaussian09. A counterpoise procedure ${ }^{29}$ was employed to correct for the effect of basis set superposition error (BSSE) for the binding energy between the drug molecule and the dimer.

X-ray photoelectron spectroscopy (XPS) analysis. X-ray photoelectron spectra (XPS) were measured on a Kratos Axis Ultra-DLD using a monochromatic Al $\mathrm{K}_{\alpha}$ X-ray source $(120 \mathrm{~W})$ and an analyser pass energy of $160 \mathrm{eV}$ (survey scans) or $20 \mathrm{eV}$ (high resolution scans); the pressure during analysis was $1 \times 10^{-9}$ Torr. All data were referenced to the $C(1 \mathrm{~s})$ signal at $285.0 \mathrm{eV}$ attributable to unsaturated C-C/C-H bonds ${ }^{22}$. Quantification and curve fitting was performed in CasaXPS ${ }^{\mathrm{TM}}$ (Version 2.3.15) using elemental sensitivity factors supplied by the manufacturer. All samples were run in triplicate.

\section{RESULTS AND DISCUSSIONS}

Predictions of drug/polymers miscibility: Hansen solubility parameters. Up to date there are several approaches employed to estimate the drug/polymer miscibility based in the determination of the solubility parameter. The theoretical approaches derived from the solubility parameter calculations suggest that compounds (e.g. drug or polymer) with similar 
$\delta$ values are likely to be miscible. This is because the energy of mixing which is released from intra-molecular interactions is balanced with the energy of mixing from intermolecular interactions ${ }^{30}$. It has been reported that compounds with $\Delta \delta<7 \mathrm{MPa}^{1 / 2}$ are likely to be miscible and compounds with $\Delta \delta>10 \mathrm{MPa}^{1 / 2}$ are likely to be less miscible or immiscible ${ }^{30}$.

It can be seen in Table 1 that the difference between the calculated solubility parameters indicate that all of the drugs used are likely to be miscible with all polymers $(\Delta \delta$ $<7 \mathrm{MPa}^{1 / 2}$ ). By using the Van Krevelen/Hoftyzer method, the calculated $\Delta \delta$ values for DPD/L100, DPD/ L100-55, PRP/L100 and PRP/L100-55 are 5.0, 3.9, 0.81 and 0.29 $\mathrm{MPa}^{1 / 2}$, respectively indicating complete drug/polymer miscibility. Similarly, $\Delta \delta$ values estimated for HCS/L100 and Df-Na/L100 are 2.59 and $3.32 \mathrm{MPa}^{1 / 2}$, respectively suggesting that both HCS and Df-Na are likely to be miscible with L100. On the other hand PMOL is unlikely to be miscible with EPO as the calculated $\Delta \delta$ falls in the range close to $7 \mathrm{MPa}^{1 / 2}$ threshold while IBU seems highly miscible with EPO ( $\Delta \delta$ is $\left.3.59 \mathrm{MPa}^{1 / 2}\right)$. However, both PMOL and IBU are miscible with VA64.

Furthermore, to determine the solubility parameters more precisely a two-dimensional approach introduced by Bagley et al. ${ }^{25}$ can be also used to predict drug-polymer miscibility (Table 1). Previous studies showed that, even though Van-Krevelen method has widely been used to screen drug/polymer miscibility, the estimated solubility parameters were not always accurate. For example, Maniruzzaman et al. ${ }^{20}$ reported a study where the difference of the calculated partial solubility parameters of the model drug PMOL and the VA64 polymer was less than $7 \mathrm{MPa}^{1 / 2}$. However, PMOL/VA64 were found immiscible and the solid-state characterisation (e.g. DSC, XRPD) showed that PMOL existed as separate amorphousamorphous phase from the polymer after extrusion. In the same study the Bagley approach provided a more accurate estimation of the drug-polymer miscibility complementing the findings from the solid-state analysis.

Therefore, the two - dimensional approach is used to determine the drug - polymer miscibility by calculating the distance $\left(\mathrm{R}_{\mathrm{a}(\mathrm{v})}\right)$ using the Pythagorean Theorem ${ }^{20}$. By this approach two components are considered miscible when $\mathrm{R}_{\mathrm{a}(\mathrm{v})} \leq 5.6 \mathrm{MPa}^{1 / 2}$. Table 1 shows that the $\delta_{\mathrm{h}}$ values of the polymers are substantially different compared to the $\delta_{\mathrm{p}}$ and $\delta_{\mathrm{d}}$. However the distances calculated for DPD/L100, DPD/L100-55, PRP/L100 and PRP/L10055 blends indicate that both DPD and PRP are miscible with L100 and L100-55 polymers. Similarly, $\mathrm{R}_{\mathrm{a}(\mathrm{v})}$ values calculated for Df-Na/L100 (6.97 $\left.\mathrm{MPa}^{1 / 2}\right)$ and HCS/L100 (2.95 $\mathrm{MPa}^{1 / 2}$ ) 
indicated that higher values for hydrogen bonding have favoured HCS to be miscible with L100 while Df-Na to be immiscible. The estimation of the Van Krevelen/Hoftyzer partial solubility parameter indicates that Df-Na is miscible with L100 but the Bagley parameter completely opposes this prediction. However, both the Van Krevelen/Hoftyzer and Bagley solubility parameters indicate that PMOL is not miscible with EPO.

The Hansen solubility parameter is considered a reliable approach to predict possible drug polymer miscibility, but the limited available data for different group contributions render this approach questionable. It does not also take in account the effect of chain conformation, including branching and linkages between monomer units and the molecular weight (MW) of compounds. These are considered important factors for the solubility of the drug molecule into polymer matrixes and thus in many cases the calculated solubility parameters provide misleading estimations of the drug/polymer miscibility.

Flory Huggins (F-H) theory for the prediction of drug/polymers interaction parameter. The Flory-Huggins $(\mathrm{F}-\mathrm{H})$ theory is another approach that describes the polymer-drug or polymer-polymer miscibility on the basis of Gibbs free energy change before and after mixing. It assumes that each molecule occupies one site in the lattice and assumes random distribution of the segments ${ }^{31}$. The presence of strong bonds or intermolecular forces (e.g. Hbonding) in solid dispersions often limits the mobility of the chains, which are forced into non-random configurations ${ }^{6,31}$. Therefore, the presence of such strong interactions in the systems makes the suitability of F-H theory unsatisfactory as it underestimates those interactions.

In order to determine the F-H interaction parameter between the investigated drugspolymers blends, the heat of fusion and melting peaks of bulk drug substances, polymers and physical blends were determined by thermal analysis. In the DSC thermograms the bulk PRP, DPD, HCS, Df-Na, PMOL and IBU showed sharp melting peaks at $166.65^{\circ} \mathrm{C}, 170.83^{\circ} \mathrm{C}$, $226.12^{\circ} \mathrm{C}, 289.60^{\circ} \mathrm{C}, 170.00^{\circ} \mathrm{C}$ and $79.50^{\circ} \mathrm{C}$, respectively with heat of fusion / enthalpy $(\Delta \mathrm{H})$ values of $126.25 \mathrm{~J} / \mathrm{g}, 124.59 \mathrm{~J} / \mathrm{g}, 114.92 \mathrm{~J} / \mathrm{g}, 161.06 \mathrm{~J} / \mathrm{g}, 137.06 \mathrm{~J} / \mathrm{g}$ and $151.17 \mathrm{~J} / \mathrm{g}$, respectively. The molecular volumes of all drugs and polymers were estimated from the functional group contribution and by using Eqs. $3 \& 4$ the average value of $\chi$ is calculated as shown in Table 2.

The negative values of the interaction parameter in Table 2 indicate that there is a net attraction force (such as dispersion, polar or hydrogen bonding) between the components in a 
binary mixture. Therefore higher absolute values of $\chi$, suggest stronger interactions between drug/polymers blends. In Table 2, it can be seen that L100 facilitates stronger interactions with different drugs compared to those of L100-55. Similarly, PMOL showed a stronger interaction with VA64 compared to that of EPO, which is in agreement with the solubility parameter calculations. As expected, IBU also showed relatively strong interactions with both EPO and VA64.

As mentioned in a previous paragraph, the F-H parameter cannot provide successful estimations when multiple stronger interactions (such as H-bonding) appear in the drug/polymer systems ${ }^{6}$. Another key limitation is that a range of experimental data is required in order to apply F-H equation, which makes the approach questionable if the data are not accurate ${ }^{8}$. Furthermore, the F-H interaction parameter cannot reveal the mechanism or site of interaction in the drug-polymer dispersions. Therefore, a new novel method that could provide both the atomistic and quantitative descriptions of drug-polymer interactions is of immense need for the development of solid dispersions for various drug-polymer systems.

Thermal analysis. DSC was used to analyze the glass transition temperature $(T \mathrm{~g})$ of all pure drugs, polymers, drug/polymer binary mixtures and extrudates (Table 3, Supp. Fig. 1-7). Thermal analysis has been used as a valuable tool to predict drug-polymer miscibility ${ }^{19,32-34}$. According to the Gordon-Taylor equation, if a drug and polymer are miscible the mixture will show a single $T \mathrm{~g}$ that ranges between the $T \mathrm{~g}$ of pure components ${ }^{20}$. Thus, the theoretical prediction of Hansen solubility parameters by using Van Krevelen method and F-H interaction parameters was complemented by DSC studies to access drug/polymer miscibility.

The DSC results of bulk drug substances, bulk polymers, physical mixtures and melt extrudates are presented in Table. 3. All physical mixtures exhibited melting peaks of the drug at slightly decreasing melting temperatures due to possible drug/polymer interactions and partial miscibility. In contrast, no drug melting transitions were observed PRP/L100, PRP/L100-55, DPD/L100 and DPD/L100 solid dispersions prepared by HME processing. The solid dispersions exhibited only a single $T \mathrm{~g}$ at temperatures between the $\mathrm{Tg}$ of the drug and the polymer, which is strong evidence that PRP and DPD are miscible with both L100 and L100-55 polymers. Similar results were also obtained for the other drug/polymer blends with an exception for the PMOL/VA64 extrudates where a phase separation was observed (PMOL and VA64 were present in two distinct amorphous phases). 
Molecular Modelling. Molecular modelling has been used extensively to assist in understanding experimental data and to predict the atomic and molecular properties that can provide guidance for experiment design. In the current study, the computation of binding strength between the drug and dimeric form of the polymer was carried out with a QM-based molecular modelling approach using commercial software package Gaussian09. In the QMbased calculations, the total energy of the system is calculated with respect to all atomic coordinates and thus the sum of electronic energy and repulsion energy between the nuclei and electrons. Because all electrons within the system are explicitly considered, the QM approach is capable of characterising with accuracy non-bonded interactions, such as hydrogen bonds and charge-charge interactions. Nonetheless, the present approach focuses on the intrinsic strength of $\mathrm{H}$ bonds and charge-charge interactions between the drug molecule and a small fragment of the polymer, which represents predominantly the polar forces present within the complex of drug-polymer carrier (Fig. 1-2). It does not take consideration of the effect of the full polymeric matrix to drug loading and the process of polymer chain swelling to absorb the drug molecules, both of which can also play a part in determining drug-polymer miscibility. Thus, the binding energy obtained from our QM calculations should be an underestimate compared to the free energy estimated using the F-H theory.

A range of polymers (in their dimeric form) and model drugs were selected to study the strength of hydrogen bonding interactions and to probe the feasibility of identifying possible drug - polymer interactions prior the manufacturing of solid dispersions. The drugpolymer interaction patterns were identified by placing the drug molecule within the proximity of the dimer and then energy optimised to a local energy minimum. Based on these optimised configurations of drug-dimer interactions, the binding energy was calculated using the following equation:

$$
E_{\text {binding }}=-\left[E_{\text {complex }}-\left(E_{\text {drug }}+E_{\text {dimer }}\right)\right]
$$

The term $E_{\text {binding }}$ is the electronic energy component and also the dominant component of the enthalpy term $(\Delta \mathrm{H})$ for the formation of the drug-dimer complexes. In all of the drug/polymers combinations primarily two different $\mathrm{H}$ bonding were detected with the donoracceptor distance at $\sim 2 \AA$. All possible $\mathrm{H}$ bonding were shown in dash line in Table 4.

Because the dimers and the drugs interact predominantly through hydrogen bonds, we interpret the calculated binding energy as a reflection of the strength of hydrogen bonds. Overall, the strength of the interactions is dependent on both the type of the donor and 
acceptor and the number of hydrogen bonds formed between the drug and the polymer (Figure 3 and Table 4). Comparisons between L100-DPD ${ }^{(a)}$ and L100-DPD ${ }^{(b)}$ and between L100-55-DPD ${ }^{(a)}$ and L100-55-DPD ${ }^{(b)}$ (superscripts (a) and (b) denote two possible drugdimer binding orientations) show that, with structurally similar polymers L100 and L100-55, the interactions formed between the tertiary amine and the carboxylate group via a proton $(21.1 \mathrm{kcal} / \mathrm{mol}$ and $20.0 \mathrm{kcal} / \mathrm{mol})$ are significantly higher than those between the alkoxy $(-\mathrm{O})$ group and the protonated carboxylate group $(12.8 \mathrm{kcal} / \mathrm{mol}$ and $15.0 \mathrm{kcal} / \mathrm{mol})$. In addition, other than the interactions involved in tertiary amines, the binding energy arising from one hydrogen bond ranges from 12.8 to $15.1 \mathrm{kcal} / \mathrm{mol}$, while the binding energy from two hydrogen bonds ranges from 16.1 to $25.3 \mathrm{kcal} / \mathrm{mol}$. On average, the binding strength of two $\mathrm{H}$-bond interactions can be stronger by $\sim 5 \mathrm{kcal} / \mathrm{mol}$ compared to interactions held through one H-bond (Figure 3). Higher binding energy represents more stable drug/polymer intermolecular interactions formed after the extrusion process ${ }^{35}$. Strong H-bonding interactions predicted by molecular dynamics suggest drug-polymer miscibility as observed by the DSC analysis.

We have also calculated the binding energy between two other polymers, VA64 and EPO with the model drugs PMOL and IBU (Table 4). The results are consistent with those from L100 and L100-55. The binding energy is predicted at $7.0 \mathrm{kcal} / \mathrm{mol}$ without hydrogen bond interactions between VA64 and IBU, while it increases to $16.7 \mathrm{kcal} / \mathrm{mol}$ when one $\mathrm{H}$ bond is formed between VA64 and IBU, and to $23.3 \mathrm{kcal} / \mathrm{mol}$ when two $\mathrm{H}$ bonds are formed between VA64 and PMOL. It is also noteworthy that again the tertiary amine from EPO and the carboxylate of IBU interacting via a proton forms the strongest interaction (27.9 $\mathrm{kcal} / \mathrm{mol}$ ). This could be attributed to the fact that the most characteristic chemical property of amines is their acid neutralizing capacity (act as bases), thus, giving rise to strong binding energy between the amine interacting with the carboxylic acid via a proton ${ }^{35}$. This is also reflected by comparing between EPO-IBU and VA64-IBU, where EPO-IBU ${ }^{(a)}$ and VA64$\mathrm{IBU}^{(\mathrm{b})}$, both held together through one H-bond between the carbonyl $(\mathrm{C}=\mathrm{O})$ group and the protonated carboxylate group, exhibit similar binding energy $(16.3 \mathrm{kcal} / \mathrm{mol}$ and 16.7 $\mathrm{kcal} / \mathrm{mol}$ ). When the donor and acceptor type is altered to tertiary amine and the carboxylic acid in EPO-IBU ${ }^{(\text {b) }}$, the binding energy increases to $27.9 \mathrm{kcal} / \mathrm{mol}$. In summary, based on the drug-dimer combinations listed in Table 4, our results indicate that the strength of the interactions is dependent on both the type of the donor and acceptor and the number of hydrogen bonds formed between the drug and the polymer. In general, addition of a hydrogen 
bond between the polymer and the drug may be accompanied by a $\sim 5$ to $8 \mathrm{kcal} / \mathrm{mol}$ increase in binding energy.

X-ray Photoelectron Spectroscopy (XPS) analysis. XPS analysis was employed to confirm the QM predictions by analysing the extruded solid dispersions of two drug-polymer formulations (PRP/L100, PRP/L100-55, DPD/L100 and DPD/L100-55). The surface elemental ratios of PRP, DPD, polymers and the extruded formulations were determined experimentally by XPS ${ }^{36-38}$ based on various surveys as depicted in Fig.4-5. This was implemented as a comparison with the anticipated theoretical values derived from the structural formula ${ }^{22}$. According to the surveys the PRP/L100, PRP/L100 55, DPD/L100 and DPD/L100-55 showed the amount of $\mathrm{N}$ atoms as $0.63 \%, 0.23 \%, 0.53 \%$ and $0.21 \%$, respectively simply indicating lower amount of $\mathrm{N}$ atom present in the final extruded formulations.

The N (1s) binding energy (BE) of $\sim 402.035 \mathrm{eV}$ (Fig. 6) in PRP and of $\sim 402.6 \mathrm{eV}$ (Fig. 7) in DPD suggests the protonation of the $\mathrm{NH}^{+}$group while the slightly higher values of $\mathrm{N}(1 \mathrm{~s})$ energy $(\sim 402.8 \mathrm{eV})$ in PRP/L100 extrudates represents further protonation effect of $\mathrm{N}$ atom as $\mathrm{NH}_{4}^{+}$. This observed $\mathrm{N}$ 1s peak at $\mathrm{BE}=\sim 402.80 \mathrm{eV}$ is in good agreement with the previously observed protonation of amine group by Beamson and Briggs ${ }^{22}$. The BE peak at $\sim 402.80 \mathrm{eV}$ (higher than typically observed for amines $\mathrm{BE}=\sim 399 \mathrm{eV}-400.5 \mathrm{eV}$ and much more for $-\mathrm{NH}_{2}^{+}$group) for $\mathrm{N} 1 \mathrm{~s}$ is an indication of C-O- $\mathrm{NH}_{2}^{+}$structure whereas the $\mathrm{O}$ atom peak at $\sim 534.40 \mathrm{eV}$ shows the same ${ }^{39,40}$. These results strongly indicate H-bonding interactions between the amine group of the API and ester/carboxyl group of the polymer (L100) (Fig. 6).

Similarly, N 1s peaks from PRP/L100-55 and DPD/L100-55 also complement the observations from PRP/L100 and DPD/L100 formulations. The N (1s) energy of $\sim 402.9 \mathrm{eV}$ in $\mathrm{DPD} / \mathrm{L} 100$ formulation suggests protonation of the amine group as observed for aforementioned PRP/L100 formulation. The BE peak at $402.90 \mathrm{eV}$ (Fig. 7) for N1s is an indication of C-O- $\mathrm{NH}_{2}{ }^{+}$structure with longer peak shift than that of PRP/L100. As before, we concluded that a strong interaction between the amine group of API and ester/carboxyl group of polymer through $\mathrm{H}$-interactions has taken place ${ }^{40-42}$.

Furthermore, the calculation of the N-coefficient for all extruded formulations indicated the strength of the intermolecular interactions within the solid dispersions. The calculated $\mathrm{N}$ coefficients for all extruded formulations are summarized in Table 5. The values 
in Table 5 clearly show that the $\mathrm{N}$ coefficient values of the active L100 extrudates are smaller than those of L100-55 extrudates. It is accepted that the lower the N-coefficient, the higher the amount of protonated $\mathrm{N}$ atoms in cationic drugs and thus the stronger the interaction between polymer and APIs.

\section{CONCLUSIONS}

In this study, we exploited the use of quantum mechanical (QM) calculations to predict drugpolymer interactions by using the drug molecule and the dimeric form of the polymer. In general, addition of a hydrogen bond between the polymer and the drug is accompanied by $\sim 5$ to $8 \mathrm{kcal} / \mathrm{mol}$ increase in binding energy. The strongest interactions however are between the tertiary amines and the carboxylate groups via a proton, with their binding energy ranging from $20.0 \mathrm{kcal} / \mathrm{mol}$ to $27.9 \mathrm{kcal} / \mathrm{mol}$. The findings from XPS analysis confirmed the site of interaction and the strength of H-bonding between the carboxyl group of anionic methacrylate co-polymers and the amine group of the active substances. The prediction of strong interactions for some of the drug-polymer blends, from the QM calculations, were in agreement with the DSC experimental findings, which proved the presence of the molecular solid dispersions of the same blends. The QM-based calculations enable the study of drugpolymer interactions with great detail at the atomistic level and are particularly suited for characterising drug-polymer interactions that contain strong hydrogen bonds or chargecharge interactions. Thus QM-based molecular modelling can broadly be applied for the development of pharmaceutical solid dispersions where traditional methods such as Van Krevelen solubility parameter or F-H parameter present a limited capacity.

\section{References}

1. Mahieu, J.; Willart, J-F.; Dudognon, E.; Danède, F.; Descamps, M. Mol. Pharmaceutics. 2013, 10 (2), pp 560-566.

2. Yuan, X.; Sperger, D.; Munson, E.J. Mol. Pharmaceutics, 2014, 11 (1), pp 329-337.

3. Tao, J.; Sun, Y.; Zhang, G.G.Z.; Yu, L. Pharm. Res. 2009, 26, 855-864.

4. Friesen, D.T.; Shanker, R.; Crew, M.; Smithey, D.T.; Curatolo, W.J.; Nightingale, J.A.S. Mol. Pharmaceutics.2008, 5,1003-1019.

5. Zhao, Y.; Inbar, P.; Chokshi, H.P.; Malick, W.; Choi, D.S. J pharm. Sci. 2011, 100, 8: 3196-3207. 
6. Flory, P.J. Principles of polymer chemistry. Ithaca, New York: Cornell University Press. 1953

7. Icoz, D.J.; Kokini, J.L. Carb Poly. 2007, 68, 59-67.

8. Higgins, J. S.; Tambasco, M.; Lipson, J. E. G. Progr. Polym. Sci. 2005, 30, 832-843.

9. Higgins, J.S.; Lipson, J.E.S.; White, R.P. Phil. Trans. R. Soc. A. 2010, 368:10091025.

10. Xiang, T-X.; Anderson, B.D. Mol. Pharmaceutics. 2013, 10 (1), pp 102-114.

11. Neibert, K.; Gosein, V.; Sharma, A.; Khan, M.; Whitehead, M.A.; Maysinger, D.; Kakkar, A. Mol. Pharmaceutics. 2013, 10 (6), pp 2502-2508.

12. Jha, P.K.; Larson, R.G. Mol. Pharmaceutics. 2014, 11 (5), pp 1676-1686.

13. Gao, Y.; Olsen, K.W. Mol. Pharmaceutics, 2013, 10 (3), pp 905-917.

14. Mollica, Y.; Baias, M.; Lewandowski, J.R.; Wylie, B.J.; Sperling, L.J.; Rienstra, C.M.; Emsley, L.; Blackledge, M. J. Phys. Chem. Lett. 2012, 3, 3657.

15. Ye, Y. K.; Bai, S.; Vyas, S.; Wirth, M. J. J. Phys. Chem. B. 2007, 111, 1189-1198.

16. Choi, P.; Kavassalis, T. A.; Rudin, A. Ind. Eng. Chem. Res. 1994, 33, 3154-3159.

17. Kavassalis, T. A.; Choi, P.; Rudin, A. Mol. Simul. 1993, 11, 229- 241.

18. Simperler, A.; Kornherr, A.; Chopra, R.; Bonnet, P. A.; Jones, W.; Motherwell, W. D. S.; Zifferer, G. J. Phys. Chem. B 2006, 110, 19678- 19684.

19. Gupta, J.; Nunes, C.; Vyas, S.; Jonnalagadd, S.J. Phys. Chem. B. 2011, 115, 2014 2023.

20. Maniruzzaman, M.; Morgan, D.J.; Mendham, A.P.; Pang, J.; Snowden, M.J.; Douroumis, D. Int J Pharm. 2013, 443(1-2),199-208.

21. Maniruzzaman, M.; Boateng, J. S.; Bonnefille, M.; Aranyos, A.; Mitchell, J. C.; Douroumis, D. Eur J Pharm Biopharm. 2012, 80(2), 433-42.

22. Gryczke, A.; Schminke, S.; Maniruzzaman, M.; Beck, J.; Douroumis D. Colloids Surf B. Biointer. 2011, 86(2), 275-84.

23. Beamson, G.; Briggs, D. J. Chem. Educ. 1993, 70, PA25.

24. Baer, D.R.; Engelhard, M.H. J Elec. Spec. and Related Pheno. 2010, 178, 415-432.

25. Hoftyzer, P.J.; Krevelen, D.W.V. Properties of polymers. Amsterdam: Elsevier, 1976.

26. Bagley, E.B.; Nelson, T.P.; Scigliano, J.M. J Paint Technol. 1971, 43, 35-42.

27. Nishi, T.; Wang, T.T. Macromolecules. 1975, 8, 909-915.

28. Hildebrand, J.; Scott, R. Solubility of non-electrolytes. $3^{\text {rd }}$ ed. New York: Reinhold.1950. 
29. Dennington, R.; Keith, T.; Millam, J. Gauss View, Version 5, Semichem Inc., Shawnee Mission KS, 2009.

30. Frisch, M. J., Trucks, G. W., Schlegel, H. B., Scuseria, G. E., Robb, M. A., Cheeseman, J. R., Scalmani, G., Barone, V., Mennucci, B., Petersson, G. A., Nakatsuji, H., Caricato, M., Li, X., Hratchian, H. P., Izmaylov, A. F., Bloino, J., Zheng, G., Sonnenberg, J. L., Hada, M., Ehara, M., Toyota, K., Fukuda, R., Hasegawa, J., Ishida, M., Nakajima, T., Honda, Y., Kitao, O., Nakai, H., Vreven, T., Montgomery, J., J. A. , Peralta, J. E., Ogliaro, F., Bearpark, M., Heyd, J. J., Brothers, E., Kudin, K. N., Staroverov, V. N., Kobayashi, R., Normand, J., Raghavachari, K., Rendell, A., Burant, J. C., Iyengar, S. S., Tomasi, J., Cossi, M., Rega, N., Millam, N. J., Klene, M., Knox, J. E., Cross, J. B., Bakken, V., Adamo, C., Jaramillo, J., Gomperts, R., Stratmann, R. E., Yazyev, O., Austin, A. J., Cammi, R., Pomelli, C., Ochterski, J. W., Martin, R. L., Morokuma, K., Zakrzewski, V. G., Voth, G. A., Salvador, P., Dannenberg, J. J., Dapprich, S., Daniels, A. D., Farkas, Ö., Foresman, J. B., Ortiz, J. V., Cioslowski, J., Fox, D. J., Gaussian 09, Revision B.1, Gaussian, Inc., Wallingford CT, 2009.

31. Greenhalgh, D.J.; Peter, W.; York, T.P. J Pharm. Sci. 1999, 88 (11), 1182-1190.

32. Donnelly, C.; Tian, Y.; Potter, C.; Jones, D.S.; Andrews, GP. Pharm Res. 2015, 32(1), 167-79.

33. Chen, Z.; Liu, Z.; Qian, F. Mol. Pharm. 2015, In press.

34. Yang, Z.; Nollenberger, K.; Albers, J.; Craig, D.; Qi S. Pharm Res. 2014. In press.

35. Coleman, M. M.; Painter, P. C. Miscible polymer blends: Background and guide for calculations and design. Lancaster, 2006. PA: DEStech Publications.

36. Graton J.; Berthelot, M.; Besseau, F.; Laurence, C. J. Org. Chem., 2005, 70 (20), pp $7892-7901$

37. Meeus,J.; Scurr, D.J.; Amssoms, K.; Davies, M.C.; Roberts, C.J.; Van den Mooter, G. Mol. Pharmaceutics, 2013, 10 (8), pp 3213-3224.

38. Watson, D.J.; Jesudason R.J.; Beaumont S.K.; Kyriakou, G.; Burton J.W.; Lambert, R.M. J. Am. Chem. Soc. 2009, 131 (40), pp 14584-14589.

39. Beaumont, S.K..; Kyriakou, G.; Lambert, R.M. J. Am. Chem. Soc. 2010, 132 (35), pp 12246-12248.

40. Davies, M.C.; Wilding, I.R.; Short, R.D.; Khan, M.A.; Watts, J.F.; Melia, C.D. Int. J Pharm.1989, 57, 183-187. 
41. Vandencasteele, N.; Reniers, F. J Elec. Spec. Rel. Phenom. 2010, 178-179, 394-408.

42. Palmer, D.; Levina, M.; Douroumis, D.; Maniruzzaman, M.; Morgan, D.J.; Farrell, T.P.; Rajabi-Siahboomi, A.R.; Nokhodchi, A. Colloids. Surf. B. Bioint. 2013,104,17480. 
Table 1: Estimated solubility parameters of different drugs and polymers using Van Krevelen /Hoftyzer and Bagley methods.

\begin{tabular}{|c|c|c|c|c|c|c|c|c|c|c|c|c|c|}
\hline \multirow[b]{2}{*}{ Comp. } & \multirow[b]{2}{*}{$\begin{array}{c}\delta p \\
\left(\mathrm{MPa}^{1 / 2}\right)\end{array}$} & \multirow[b]{2}{*}{$\begin{array}{c}\delta d \\
\left(\mathrm{MPa}^{1 / 2}\right)\end{array}$} & \multirow[b]{2}{*}{$\begin{array}{c}\delta h \\
\left(\mathrm{MPa}^{1 / 2}\right)\end{array}$} & \multirow[b]{2}{*}{$\begin{array}{c}\delta v \\
\left(\mathrm{MPa}^{1 / 2}\right)\end{array}$} & \multirow[b]{2}{*}{$\begin{array}{c}\delta \\
\left(\mathrm{MPa}^{1 / 2}\right)\end{array}$} & \multicolumn{4}{|c|}{ Van Krevelen $(\Delta \delta)$} & \multicolumn{4}{|c|}{ Bagley (Ra(v) } \\
\hline & & & & & & $\begin{array}{c}\Delta \delta \mathrm{L100}^{1 / 2} \\
\left(\mathrm{MPa}^{1 / 2}\right)\end{array}$ & $\begin{array}{c}\Delta \delta \text { L100- } \\
55 \\
(\mathrm{MPa} 1 / 2)\end{array}$ & $\begin{array}{l}\Delta \delta \text { EPO } \\
\left(\mathrm{MPa}^{1 / 2}\right)\end{array}$ & $\begin{array}{c}\Delta \delta \mathrm{VA64}^{1 / 2} \\
\left(\mathrm{MPa}^{1 / 2}\right)\end{array}$ & $\begin{array}{c}\operatorname{Ra}(v) \\
\operatorname{L100}\end{array}$ & $\begin{array}{c}\mathbf{R a}(\mathbf{v}) \\
\mathbf{L 1 0 0 - 5 5}\end{array}$ & $\begin{array}{c}\text { Ra(v) } \\
\text { EPO }\end{array}$ & $\begin{array}{l}\text { Ra(v) } \\
\text { VA64 }\end{array}$ \\
\hline PRP & 3.67 & 19.30 & 9.90 & 19.64 & 21.94 & 0.81 & 0.29 & - & - & 3.26 & 4.67 & - & - \\
\hline DPD & 4.05 & 16.39 & 5.44 & 16.89 & 17.75 & 5.0 & 3.9 & - & - & 3.59 & 4.22 & - & - \\
\hline Df-Na & 3.32 & 24.65 & 7.82 & 24.87 & 26.07 & 3.32 & - & - & - & 6.97 & - & - & - \\
\hline HCS & 8.02 & 19.04 & 14.65 & 20.67 & 25.34 & 2.59 & - & - & - & 2.95 & - & - & - \\
\hline PMOL & 7.93 & 19.67 & 13.96 & 21.20 & 25.39 & - & - & 6.49 & 5.79 & - & - & 13.16 & 12.17 \\
\hline IBU & 5.76 & 18.47 & 10.04 & 19.35 & 21.80 & - & - & 2.90 & 2.20 & - & - & 4.21 & 5.87 \\
\hline L100 & 0.41 & 19.31 & 12.03 & 19.31 & 22.75 & - & - & - & - & - & - & - & - \\
\hline L100-55 & 0.25 & 18.22 & 11.69 & 18.22 & 21.65 & - & - & - & - & - & - & - & - \\
\hline EPO & 0.65 & 17.89 & 6.08 & 17.90 & 18.90 & - & - & - & - & - & - & - & - \\
\hline VA64 & 18.0 & 0.64 & 18.01 & 7.73 & 19.60 & - & - & - & - & - & - & - & - \\
\hline
\end{tabular}

$R_{a(v)}=\sqrt{\left(\delta_{v 2}-\delta_{v 1}\right)^{2}+\left(\delta_{h 2}-\delta_{h 1}\right)^{2}}$ 
Table 2: Calculation of $\mathrm{F}-\mathrm{H}$ interaction parameter of different Drug-Polymer extruded formulations.

\begin{tabular}{|l|c|c|c|}
\hline Formulations & $\begin{array}{c}\text { Volume Fractions } \\
(\boldsymbol{ø})\end{array}$ & $\begin{array}{c}\text { Nishi-Wang } \\
(-\boldsymbol{\chi})\end{array}$ & $\begin{array}{c}\text { Hildebrand - Scott } \\
\left(-\boldsymbol{\chi} \mathbf{x} 10^{-4}\right)\end{array}$ \\
\hline PRP/L100 & $0.1: 0.9$ & 0.22 & 2.89 \\
\hline PRP/L100-55 & $0.1: 0.9$ & 0.08 & 0.37 \\
\hline DPD/L100 & $0.1: 0.9$ & 0.20 & 1.10 \\
\hline DPD/L100-55 & $0.1: 0.9$ & 0.07 & 0.67 \\
\hline HCS/L100 & $0.1: 0.9$ & 0.21 & 0.15 \\
\hline Df-Na/L100 & $0.3: 0.7$ & 0.01 & 1.60 \\
\hline PMOL/VA64 & $0.5: 0.5$ & 2.12 & 0.20 \\
\hline PMOL/EPO & $0.5: 0.5$ & 0.38 & 0.35 \\
\hline IBU/EPO & $0.4: 0.6$ & 0.81 & 0.20 \\
\hline IBU/VA64 & $0.4: 0.6$ & 0.61 & \\
\hline
\end{tabular}


Table 3: Thermal transitions of pure drugs, polymers and binary mixtures.

\begin{tabular}{|c|c|c|c|}
\hline & \multicolumn{2}{|c|}{$\begin{array}{c}\text { Glass transition } \\
\qquad\left({ }^{0} \mathrm{C}\right)\end{array}$} & $\begin{array}{c}\text { Melting endotherm/ } \\
\text { Enthalpy } \\
\left({ }^{\mathbf{0}} \mathrm{C} / \Delta \mathbf{H}, \mathbf{J g}^{-1}\right)\end{array}$ \\
\hline PRP & \multicolumn{2}{|c|}{36.22} & $166.65 / 126.25$ \\
\hline DPD & \multicolumn{2}{|c|}{14.13} & $170.82 / 124.59$ \\
\hline Df-Na & \multicolumn{2}{|c|}{-} & $289.61 / 161.06$ \\
\hline $\mathrm{HCS}$ & \multicolumn{2}{|c|}{82.45} & $226.12 / 114.92$ \\
\hline PMOL & \multicolumn{2}{|c|}{24.55} & $168.84 / 33.40$ \\
\hline IBU & \multicolumn{2}{|c|}{-} & $77.9 / 121.30$ \\
\hline L100 & \multicolumn{2}{|c|}{164.38} & - \\
\hline L100-55 & \multicolumn{2}{|c|}{83.97} & - \\
\hline EPO & \multicolumn{2}{|c|}{48.38} & - \\
\hline VA64 & \multicolumn{2}{|c|}{105.0} & - \\
\hline \multicolumn{4}{|c|}{ Physical mixtures (PM) and extruded formulations (EXT) } \\
\hline & $\begin{array}{l}\text { PM } \\
\left({ }^{\circ} \mathrm{C}\right)\end{array}$ & $\begin{array}{l}\text { EXT } \\
\left({ }^{\circ} \mathrm{C}\right)\end{array}$ & $\begin{array}{l}\text { PM } \\
\left({ }^{\circ} \mathrm{C}\right)\end{array}$ \\
\hline PRP/L100 & 98.82 & 74.84 & 162.41 \\
\hline PRP/L100-55 & 71.16 & 63.36 & 153.62 \\
\hline DPD/L100 & 114.46 & 76.56 & 139.19 \\
\hline $\mathrm{DPD} / \mathrm{L} 100-55$ & 74.15 & 62.11 & 153.62 \\
\hline PMOL/VA64* & 102.22 & $27.57,93.47$ & 131.32 \\
\hline PMOL/EPO & 79.38 & 56.76 & 159.96 \\
\hline IBU/VA64 & 54.83 & 29.49 & 76.6 \\
\hline IBU/EPO & 57.40 & 15.57 & 76.35 \\
\hline
\end{tabular}

* Two Tgs were observed for the extruded blend due to phase separation. 
Table 4: The calculated drug-dimer binding energy using Gaussian09 (energy in kcal $/ \mathrm{mol}$ ). The top table is for the dimeric forms of polymer L100 and L100-55 and model drugs PRP and DPD, while the bottom table is for the dimeric forms of polymer VA64 and EPO and model drugs PMOL and IBU. Superscripts (a) and (b) denote two possible drug-dimer binding orientations, which were determined by positioning the drug molecule in two different orientations (based on its H-bond donor/acceptor groups) relative to the position of the dimer prior to the QM optimisation.

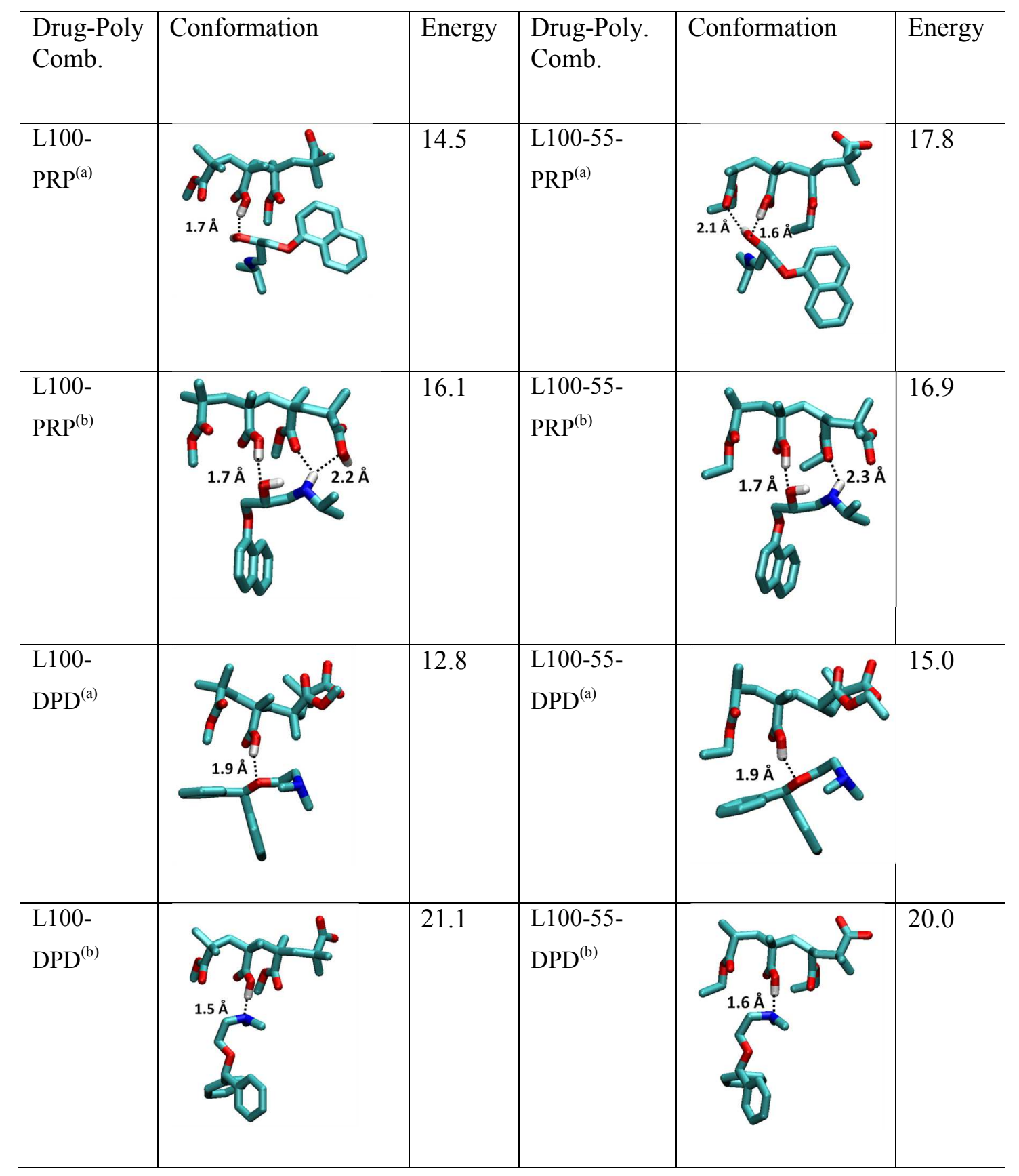



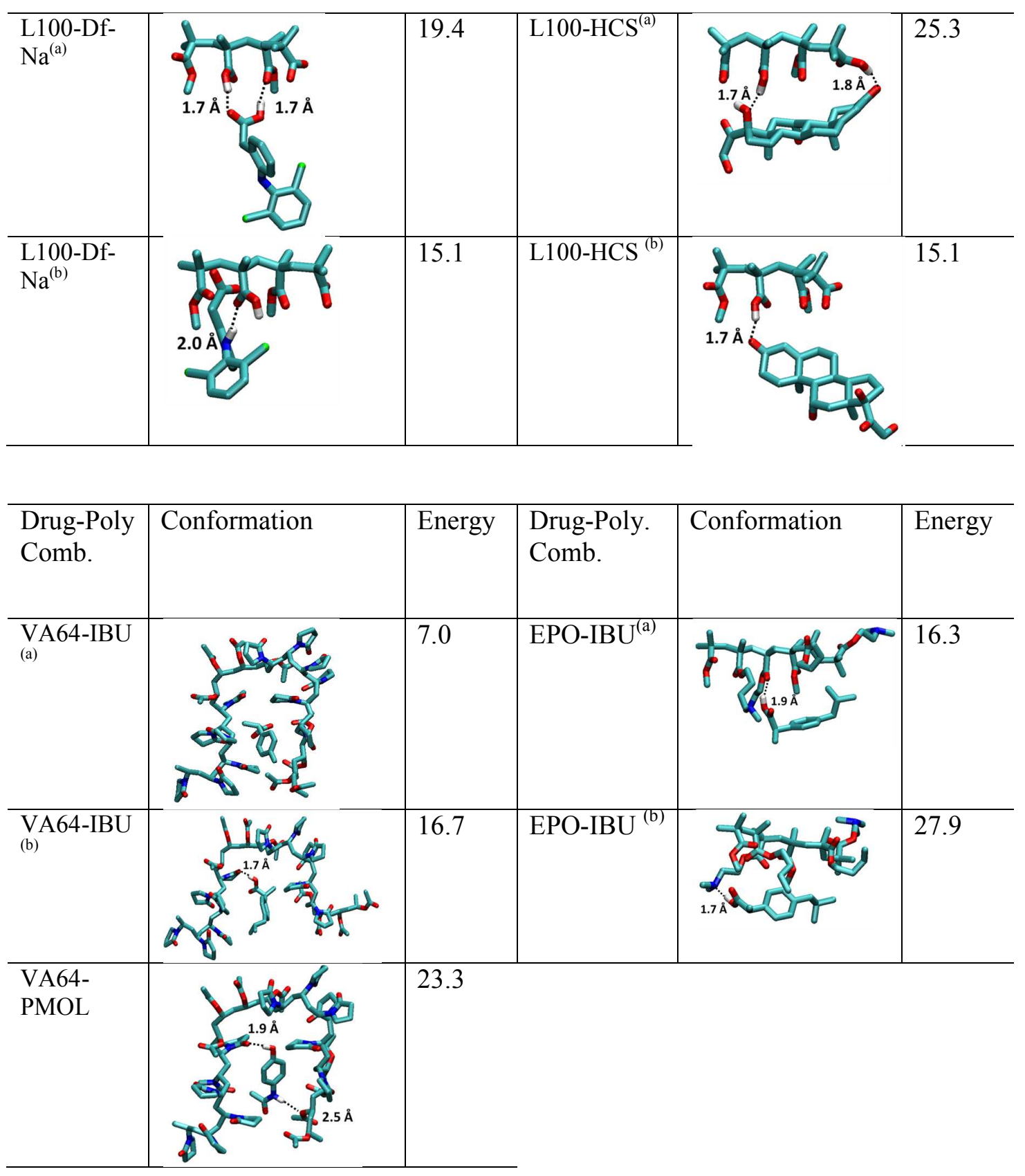

Table 5: $\mathrm{N}$ coefficients of the extruded formulations

\begin{tabular}{|c|c|c|c|}
\hline \multirow{2}{*}{ Formulations } & \multicolumn{2}{|c|}{ N 1s Binding Energy } & \multirow{2}{*}{ Calculated N Coefficient } \\
\cline { 2 - 3 } & $\mathbf{1}^{\text {st }}$ Fitting (eV) & $\mathbf{2}^{\text {nd }}$ Fitting (eV) & \\
\hline PRP/L100 & 63 & 100 & 0.63 \\
\hline PRP/L100-55 & 58.51 & 49.49 & 1.18 \\
\hline DPD/L100 & 45.97 & 54.03 & 0.85 \\
\hline DPD/L100-55 & 51.19 & 48.81 & 1.05 \\
\hline
\end{tabular}




\section{Figures caption list}

Fig. 1 Molecular modelling of PRP and L100 or L100-55 pairs (Gaussian09).

Fig. 2 Molecular modelling of DPD with different polymers (energy optimised to local minima at the M06-2x/6-31G** level and verified by frequency calculations using Gaussian09).

Fig. 3 Binding energy as arranged based on the number of hydrogen bonds (red and blue columns for one $\mathrm{H}$ bond while green for two $\mathrm{H}$ bonds) between the dimeric structure of the polymer and the model drugs. Red columns represent the binding energy involved in tertiary amines.

Fig. 4 XPS surveys of pure PRP, DPD, L100 and L100-55 showing BE peaks of C 1s, $\mathrm{O} 1 \mathrm{~s}, \mathrm{~N} 1 \mathrm{~s}$ and $\mathrm{Cl} 2 \mathrm{p}$ atoms and their area ratios.

Fig. 5 XPS surveys of DPD and PRP based extruded formulations with L100 and L100-55 polymers (C 1s, O 1s, $\mathrm{N} 1 \mathrm{~s}$ and $\mathrm{Cl} 2 \mathrm{p}$ atoms and their area ratios).

Fig. 6 Molecular structure of PRP and $\mathrm{N}$ 1s BE peaks of PRP and extruded formulations (from the peak fitting using CasaXPS ${ }^{\mathrm{TM}}$ - Version 2.3.15).

Fig. 7 DPD molecular structure and its N 1s BE peaks with DPD/L100 and DPD/L10055 extruded formulations (peak fitting performed using CasaXPS $^{\mathrm{TM}}$ - Version 2.3.15). 


\section{Graphical Abstract}
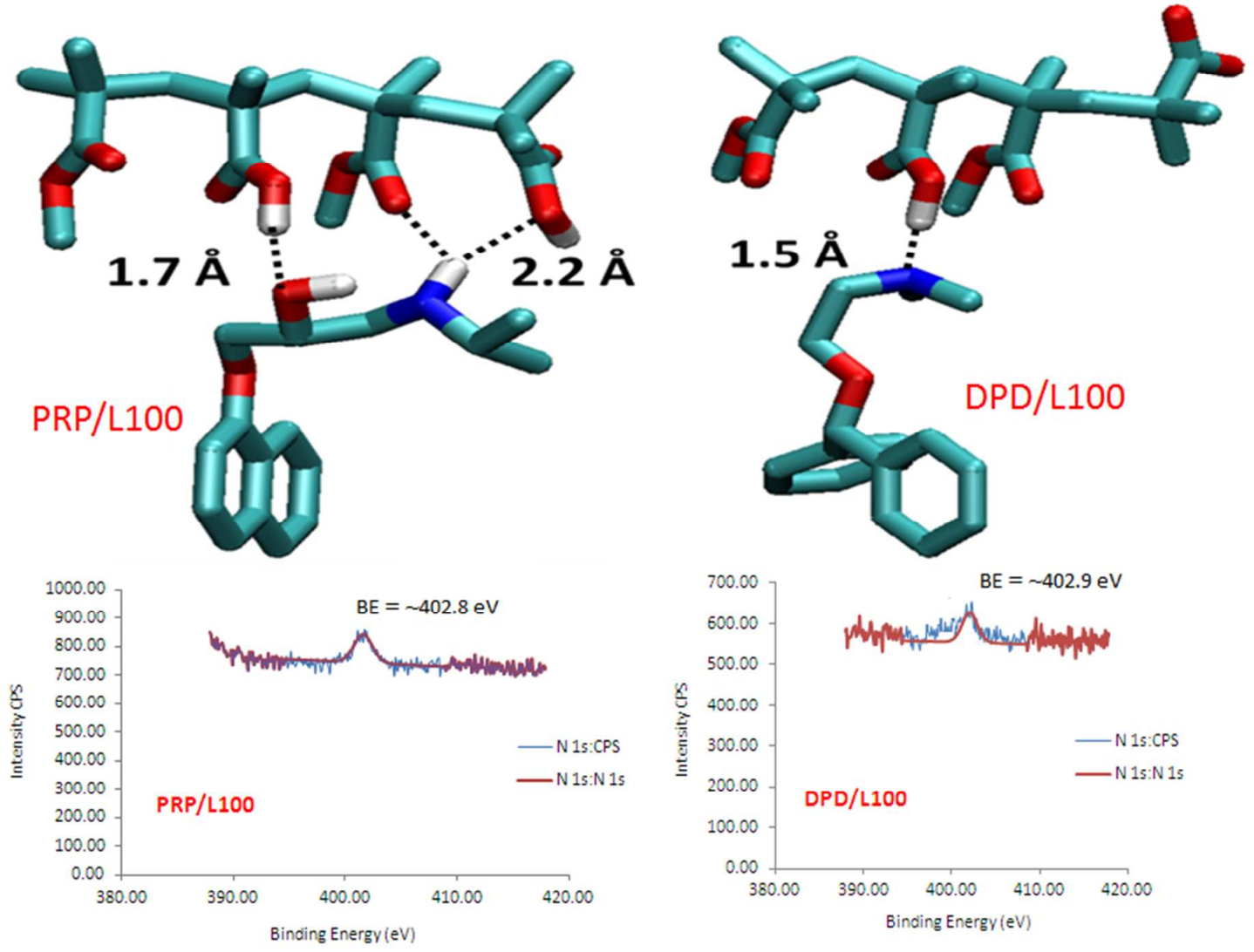

34

35

36

37

38

39

40

41

42

43

44

45

46

47

48

49

50

51

52

53

54

55

56

57

58

59 

Molecular modelling of DPD with different polymers (energy optimised to local minima at the B3LYP/6-31G* level and verified by frequency calculations using Gaussian09). $260 \times 203 \mathrm{~mm}(96 \times 96$ DPI)




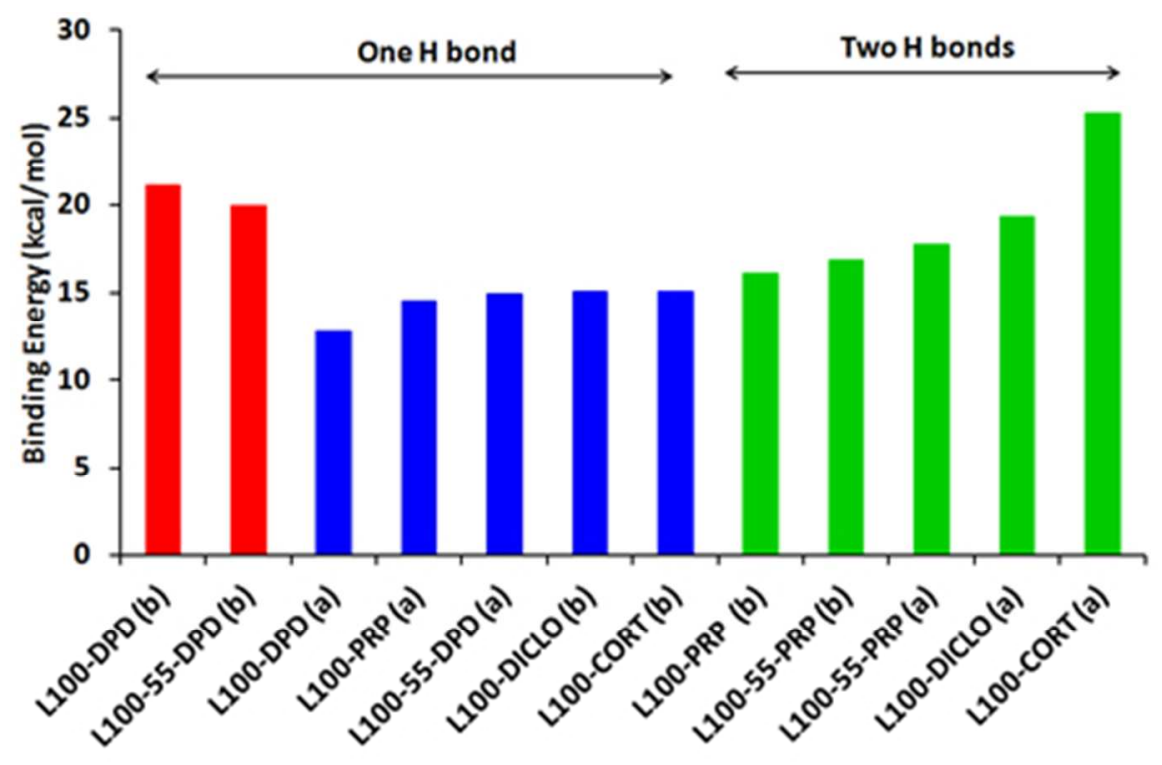

Binding energy as arranged based on the number of hydrogen bonds (red and blue columns for one $\mathrm{H}$ bond while green for two $\mathrm{H}$ bonds) between the dimeric structure of the polymer and the model drugs. Red columns represent the binding energy involved in tertiary amines.

\section{$118 \times 78 \mathrm{~mm}(96 \times 96 \mathrm{DPI})$}


1

2

3

4

5

6

7

10

11

12

14

15

16

17

18

19

20

21

22

23

24

25

26

27

28

29

30

31

32

33

34

35

36

37

38

39

40

41

42

43

44

45

46

47

48

49

50

51

52

53

54

55

56

57

58

59

60
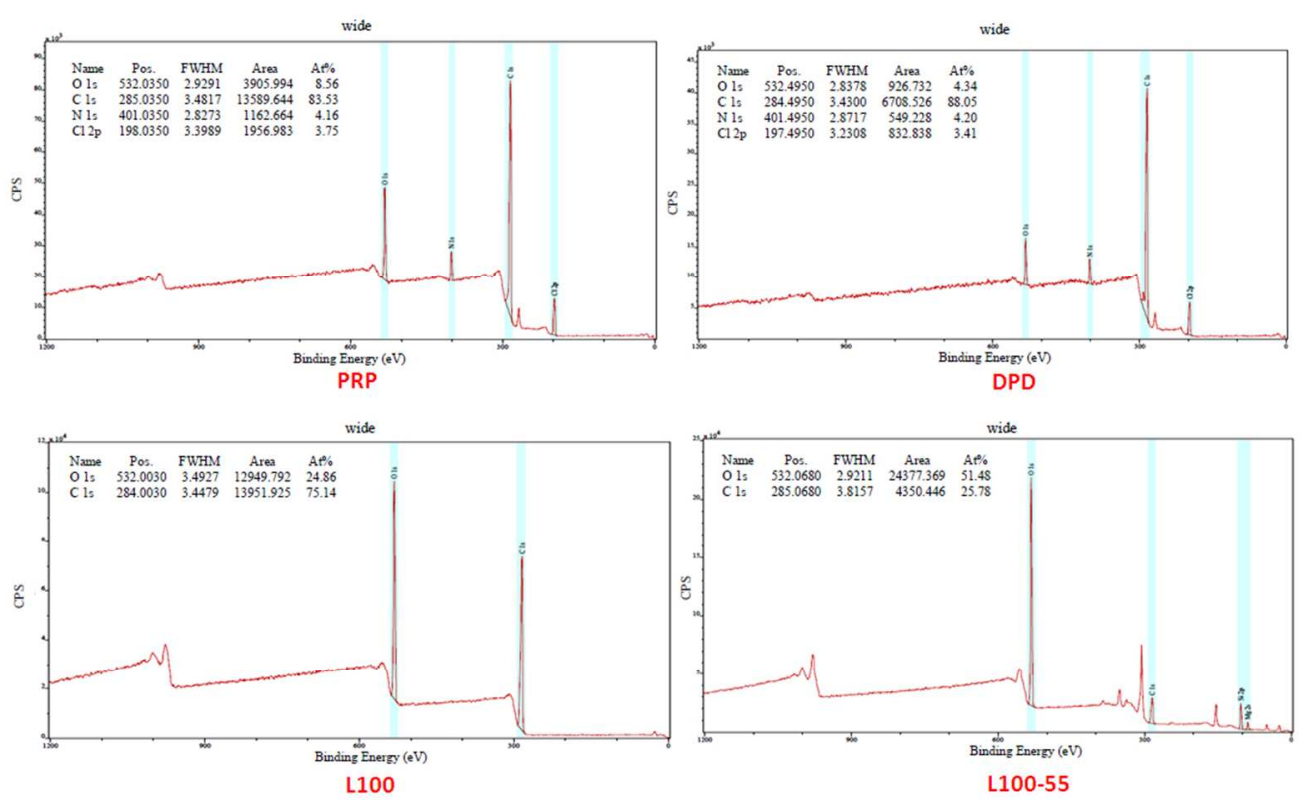

XPS surveys of pure PRP, DPD, L100 and L100-55 showing BE peaks of $C 1 \mathrm{~s}, \mathrm{O} 1 \mathrm{~s}, \mathrm{~N}$ 1s and $\mathrm{Cl} 2 \mathrm{p}$ atoms and their area ratios.

$288 \times 174 \mathrm{~mm}(96 \times 96 \mathrm{DPI})$ 

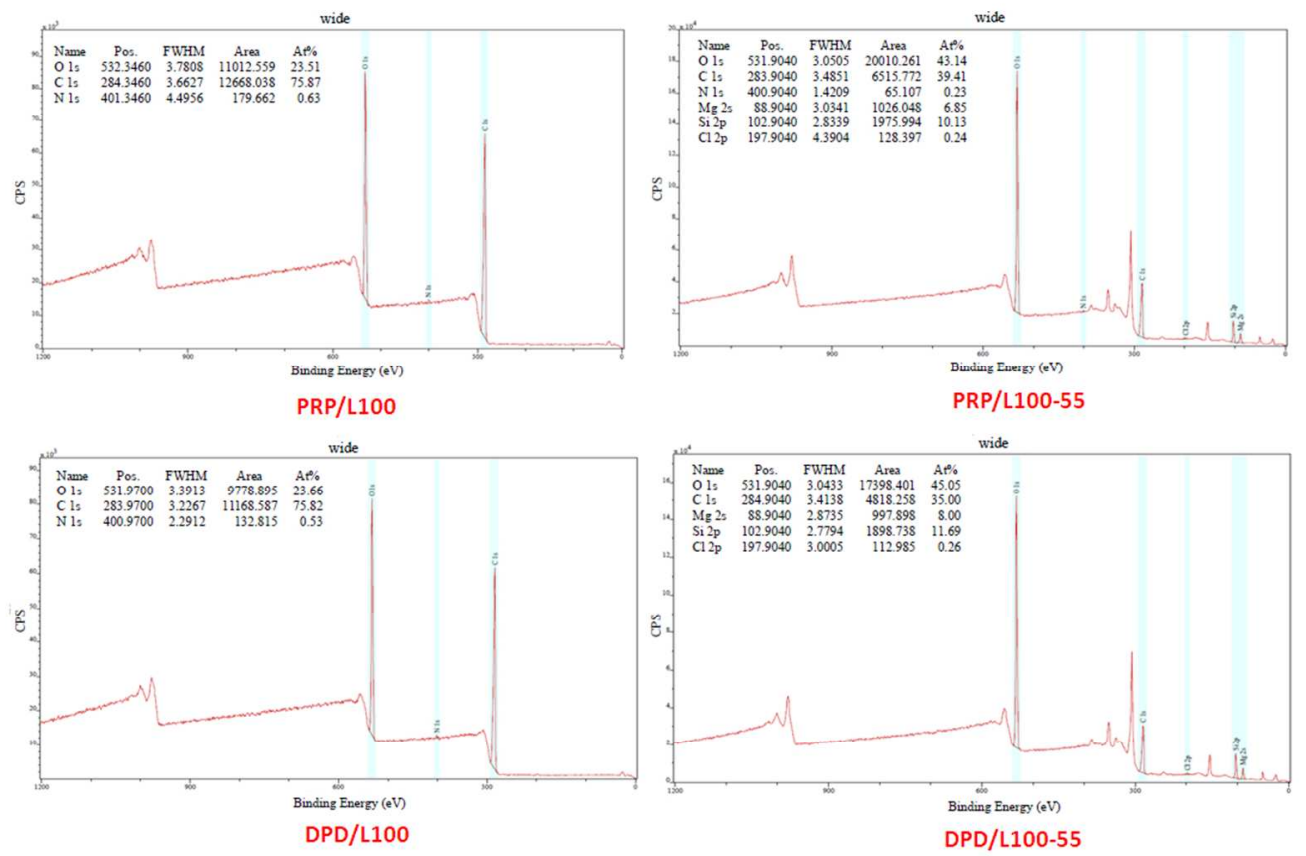

XPS surveys of DPD and PRP based extruded formulations with L100 and L100-55 polymers (C 1s, O 1s, N $1 \mathrm{~s}$ and $\mathrm{Cl} 2 \mathrm{p}$ atoms and their area ratios). $288 \times 194 m m$ (96 x 96 DPI) 
1

2

3

4

5

6

7

8

9

10

11

12

13

14

15

16

17

18

19

20

21

22

23

24

25

26

27

28

29

30

31

32

33

34

35

36

37

38

39

40

41

42

43

44

45

46

47

48

49

50

51

52

53

54

55

56

57

58

59

60
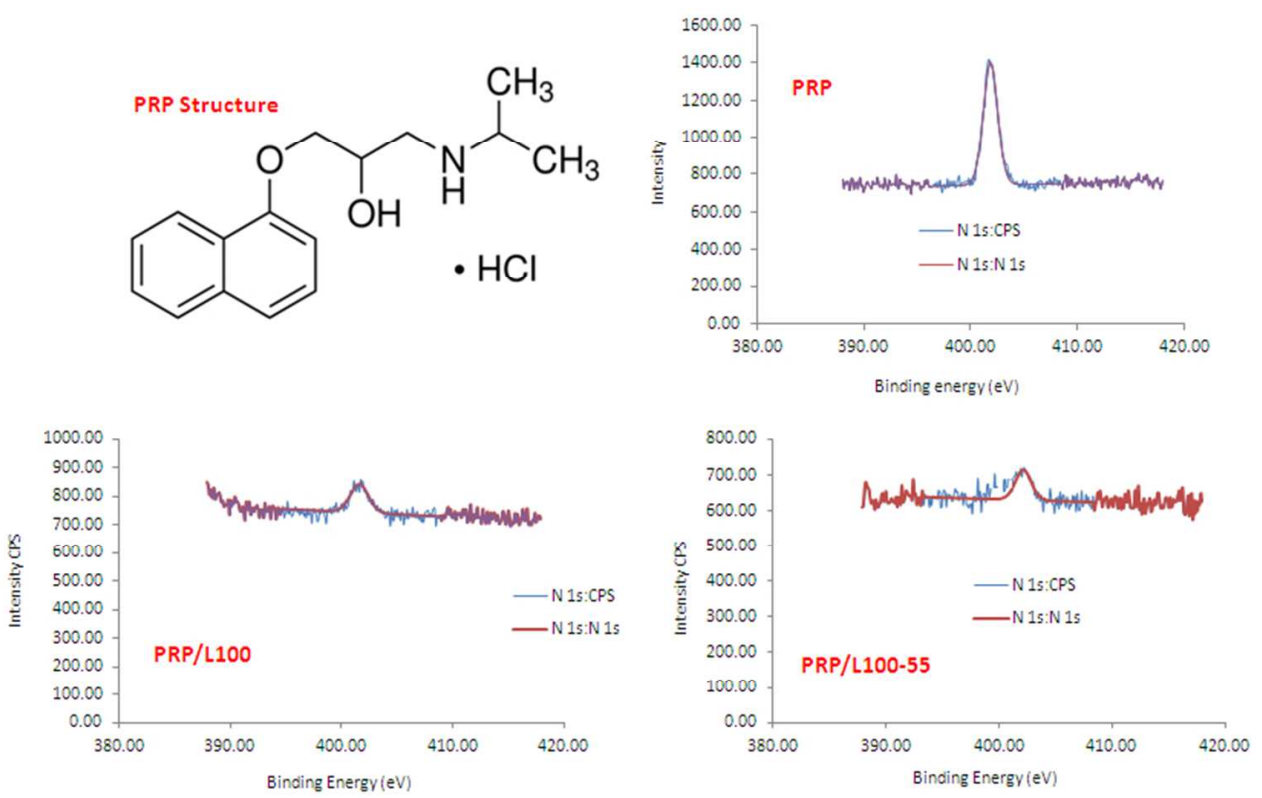

Molecular structure of PRP and N 1s BE peaks of PRP and extruded formulations (from the peak fitting using CasaXPSTM - Version 2.3.15).

$225 \times 139 \mathrm{~mm}(96 \times 96 \mathrm{DPI})$ 

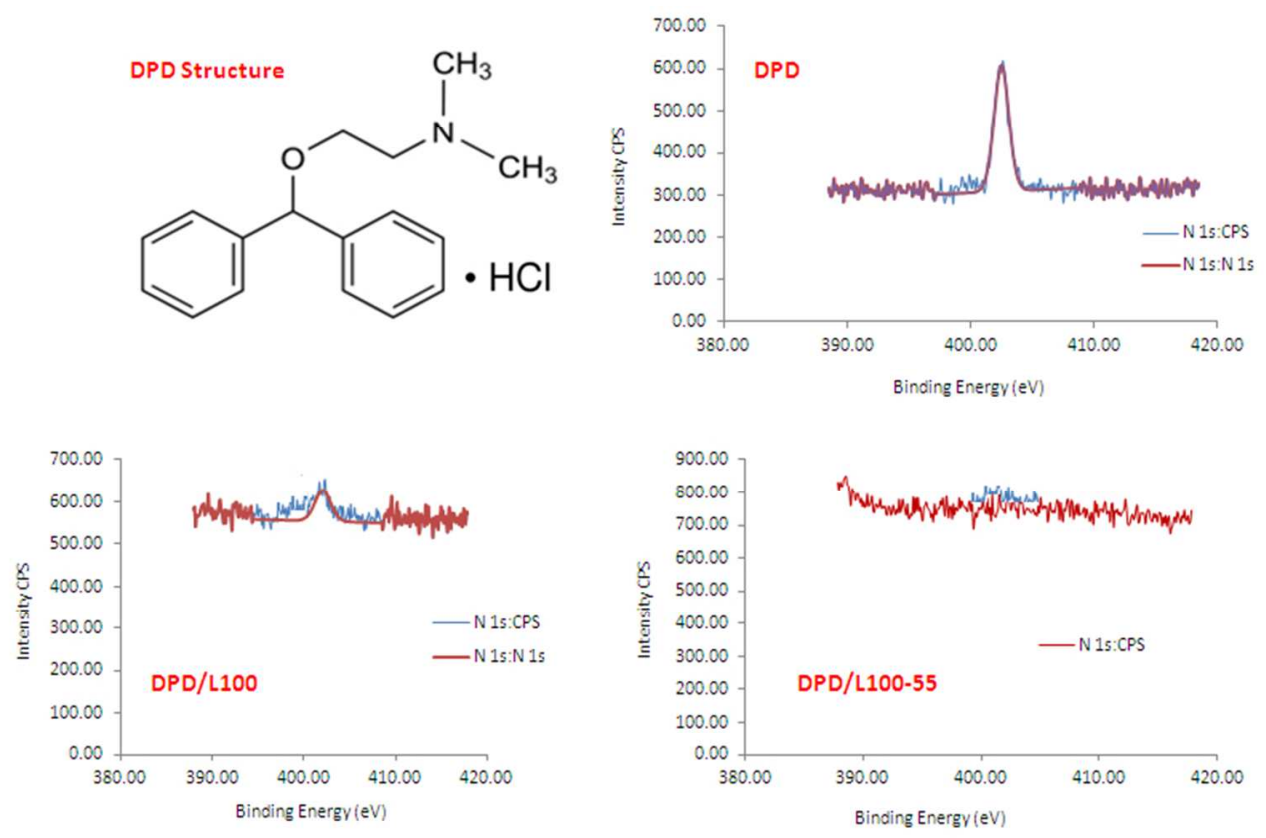

DPD molecular structure and its N 1s BE peaks with DPD/L100 and DPD/L100-55 extruded formulations (peak fitting performed using CasaXPSTM - Version 2.3.15). $215 \times 140 \mathrm{~mm}$ (96 x 96 DPI) 